\title{
A Novel Island Detection Threshold Setting Using Phasor Measurement Unit Voltage Angle in a Distribution Network
}

\author{
Ahmed Amirul Arefin ${ }^{1}\left(\mathbb{D}\right.$, Khairul Nisak Binti Md. Hasan ${ }^{1, *}$, Mohammad Lutfi Othman ${ }^{2, *} \mathbb{D}$, \\ Mohd Fakhizan Romlie ${ }^{1}$ (D), Nordin Saad ${ }^{1}$, Nursyarizal Bin Mohd Nor ${ }^{1}$ and Mohd Faris Abdullah ${ }^{3}$ (D) \\ 1 Department of Electrical and Electronics Engineering, Universiti Teknologi PETRONAS, \\ Perak 32610, Malaysia; amirul_19001788@utp.edu.my (A.A.A.); fakhizan.romlie@utp.edu.my (M.F.R.); \\ nordiss@utp.edu.my (N.S.); nursyarizal_mnor@utp.edu.my (N.B.M.N.) \\ 2 Advanced Lightening Power and Energy Research (ALPER), Department of Electrical and Electronics \\ Engineering, Faculty of Engineering, Universiti Putra Malaysia, Selangor 43400, Malaysia \\ 3 Department of Electrical and Electronics Engineering, Xiamen University Malaysia, Sepang 43900, Malaysia; \\ farisk64@yahoo.com \\ * Correspondence: khairulnisak.hasan@utp.edu.my (K.N.B.M.H.); lutfi@upm.edu.my (M.L.O.); \\ Tel.: +60-10-5655029 (K.N.B.M.H.); +60-19-2755209 (M.L.O.)
}

check for

updates

Citation: Arefin, A.A.; Hasan, K.N.B.M.; Othman, M.L.; Romlie, M.F.; Saad, N.; Nor, N.B.M.; Abdullah, M.F. A Novel Island Detection Threshold Setting Using Phasor Measurement Unit Voltage Angle in a Distribution Network. Energies 2021, 14, 4877. https://doi.org/10.3390/ en14164877

Academic Editor: Pierluigi Siano

Received: 15 June 2021

Accepted: 28 June 2021

Published: 10 August 2021

Publisher's Note: MDPI stays neutral with regard to jurisdictional claims in published maps and institutional affiliations.

Copyright: (c) 2021 by the authors. Licensee MDPI, Basel, Switzerland. This article is an open access article distributed under the terms and conditions of the Creative Commons Attribution (CC BY) license (https:// creativecommons.org/licenses/by/ $4.0 /)$.

\begin{abstract}
Islanding detection needs are becoming a pivotal constituent of the power system, since the penetration of distributed generators in the utility power system is continually increasing. Accurate threshold setting is an integral part of the island detection scheme since an inappropriate threshold might cause a hazardous situation. This study looked at the islanding conditions as well as two transient faults, such as a single line to ground fault and a three-phase balance fault, to assess the event distinguishing ability of the proposed method. Therefore, the goal of this research was to determine the threshold of the island if the distributed generator (DG) capacity is greater than the connected feeder load, which is the over-frequency island condition, and if the DG capacity is less than the connected feeder load, which is the under-frequency island condition. The significance of this research work is to propose a new island detection threshold setting method using the slip angle and acceleration angle that comes from phasor measurement unit (PMU) voltage angle data. The proposed threshold setting method was simulated in the PowerWorld simulator on a modified IEEE 30 bus system equipped with DG. There are three different interconnection scenarios in the test system and the performance of the proposed method shows that getting the island threshold for all the scenarios requires a single time step or 20 mile seconds after incepting an island into the network. In addition, it can distinguish between the real islanding threshold and the transient faults threshold.
\end{abstract}

Keywords: phasor measurement unit; under frequency; over frequency; distribution network; slip angle; acceleration angle

\section{Introduction}

The transition from a traditional grid to a microgrid with the combination of DG units is happening at a rapid pace around the world [1]. Despite the great economic and environmental well-being provided by renewable DG, it has its own drawbacks, such as difficulties in power system operation, control, and security [2]. Voltage fluctuations, power fluctuations, and power quality problems are all caused by non-dispatchable renewable energy sources' intermittent behavior [3]. The microgrid's DG units are still energized to satisfy local demand in an island state, but the microgrid is electrically disconnected from the utility grid [4]. As a result, island identification in a microgrid is unavoidable in order to fulfill its role. Furthermore, in the case of unscheduled islanding, the system's behavior may be unpredictable [5]. IEEE 1547-2003 and IEEE 1547a-2014 guidelines recommend that DG be disconnected within $2 s$ [4]. The microgrid may be disconnected from the rest of the network for an isolated service in the event of a recurrent fault in the utility [6]. If a 
fault occurs inside the microgrid and the circuit breaker is opened, the islanding detection algorithm can work to isolate the smallest possible faulted region of the microgrid [7]. Furthermore, the islanding detection algorithm should have the ability to distinguish between true islanding and transient events such as the initiation and clearing of a fault in a nearby feeder [8]. Local and remote islanding detection techniques (IDTs) have been described in the literature [9]. IDTs are divided into two categories based on local measurements: passive and active techniques. When the power difference between the DG and the load is very low or zero, the passive methods fail [10]. The advantage of the active technique is the minimum non-detecting zone (NDZ), but it decreases the power quality [11-18]. The combination of active and passive techniques is able to decrease the NDZ and also maintain the desired power quality, but the algorithm is unable to differentiate between the events [7,19-21]. An effective islanding detection algorithm should be able to detect all possible islanding scenarios, but most schemes currently focus only on grid-side faults [22].

An effective and fast monitoring system using systemic principal component analysis was proposed in [19]. However, their scheme would have necessitated longer computational time. In [23], they proposed a multi-functional fault detection algorithm by using PMU data of voltage angle with dynamic monitoring and supervision. Pattern recognition techniques for island events based on transient signals have been discussed [24,25], but the implementation of this proposed system is extremely difficult. Utilizing PMU data for detecting islanding events has been proposed [26,27]. In [26], they used frequency difference to detect islanding events, whereas [27] used the change in phase angles, but those algorithms are not effective for the match frequency condition due to the minimal voltage and frequency excursion in the match frequency condition.

For detecting islanding events, decision tree (DT) approaches show higher accuracy performance [28,29]. The supervisory control and data acquisition (SCADA) system is a very popular approach for detecting islanding events but is unable to feedback accurately due to the conveying delay and also the higher investment required for the installment [30]. An islanding detection scheme using the voltage angle difference between two PMUs was discussed in [31], where detection time showed better performance but the under-frequency and over-frequency islanding condition performance was absent from their algorithm. Differentiating the islanding operation with the normal operation using PMU voltage angle was discussed in [32], where a simulation was conducted in the IEEE 30 bus system, but they did not consider the transient fault event. In [33,34], they proposed a probabilistic component analysis-based islanding detection method. The proposed method showed faster detection without false triggers but the scheme was collapsed detect when phase angle and frequency are well matched during islanding events. A voltage angle and current angle-based islanding detection algorithm was proposed in [35,36], where they lessened the false triggers but did not show any performance analysis on the match frequency islanding condition. A voltage magnitude-based islanding detection method was proposed in $[37,38]$, but the proposed method was unable to detect islanding of the minimal power exchange condition due to the local detection scheme. In [39], they calculated the current flow through the breaker, and in that case, an island was detected before opening the breaker. However, in that case transmission loss was considered as the DG islanding conditions. In [40], they used a ridgilet probabilistic neural network to detect the islanding and were able to detect islanding but did not consider the transient faults.

The goal of this research was to figure out the island thresholds with a minimum time and distinguish islands from transient faults. The challenges of this research work were (1) the phase angle value of the different DG islanding conditions being located in dissimilar regions, (2) setting a single threshold that would be applicable for the under-frequency and over-frequency islanding conditions, and (3) distinguishing between the real islanding event and the transient fault. This research work proposes a new slip angle and acceleration angle-based island detection threshold setting method.

The proposed island threshold setting method is different from other schemes because it is able to distinguish between the real islanding threshold and the transient fault threshold 
by a single time step. According to other literature, most islanding detection schemes do not distinguish transient faults from the island event, which means that detecting a transient fault as an island event is possible. However, in reality, a transient fault is not island event. However, the studies that attempted to address this issue discovered a longer island detection time as a result of the inappropriate threshold setting. Therefore, this research work identified that specific research gap and worked to set the appropriate island detection thresholds, which ensure event differentiation with faster island detection. The remainder of the paper is organized as follows: The methodology is explained in Section 2. The simulation of the system is in Section 3, and the results discussion is in Section 4.

\section{Methodology}

\subsection{Slip Angle and Acceleration Angle}

The proposed islanding detection threshold determining methodology focuses on the slip angle and acceleration angle. This scheme calculates the slip angle based on the rate of change of the angle difference of the DG and the utility bus with respect to the time, and the acceleration angle is the rate of change of the slip angle with respect to the time. This proposed novel slip angle and acceleration angle theory was motivated by $[41,42]$.

$$
\begin{gathered}
\text { Slip Angle }=\frac{d}{d t} \Delta v \\
\text { Acceleration Angle }=\frac{d}{d t}\left(\frac{d}{d t} \Delta v\right)
\end{gathered}
$$

where $\Delta v$ is the voltage angle difference between the DG and the utility bus. However, the slip angle and acceleration angle come from the PMU voltage angle data.

\subsection{Proposed Island Detection Threshold Setting Method}

To detect island events in a timely manner, a substantial part involves setting the threshold precisely to detect islands as well as differentiate the transient faults. Generally, if the threshold is not set properly the scheme cannot detect islanding events or may require more time. Figure 1 shows the proposed threshold setting method of the islanding event and transient fault. There are five units in this proposed method: bus, determining load threshold, island inception, threshold value calculation, and threshold setting. 


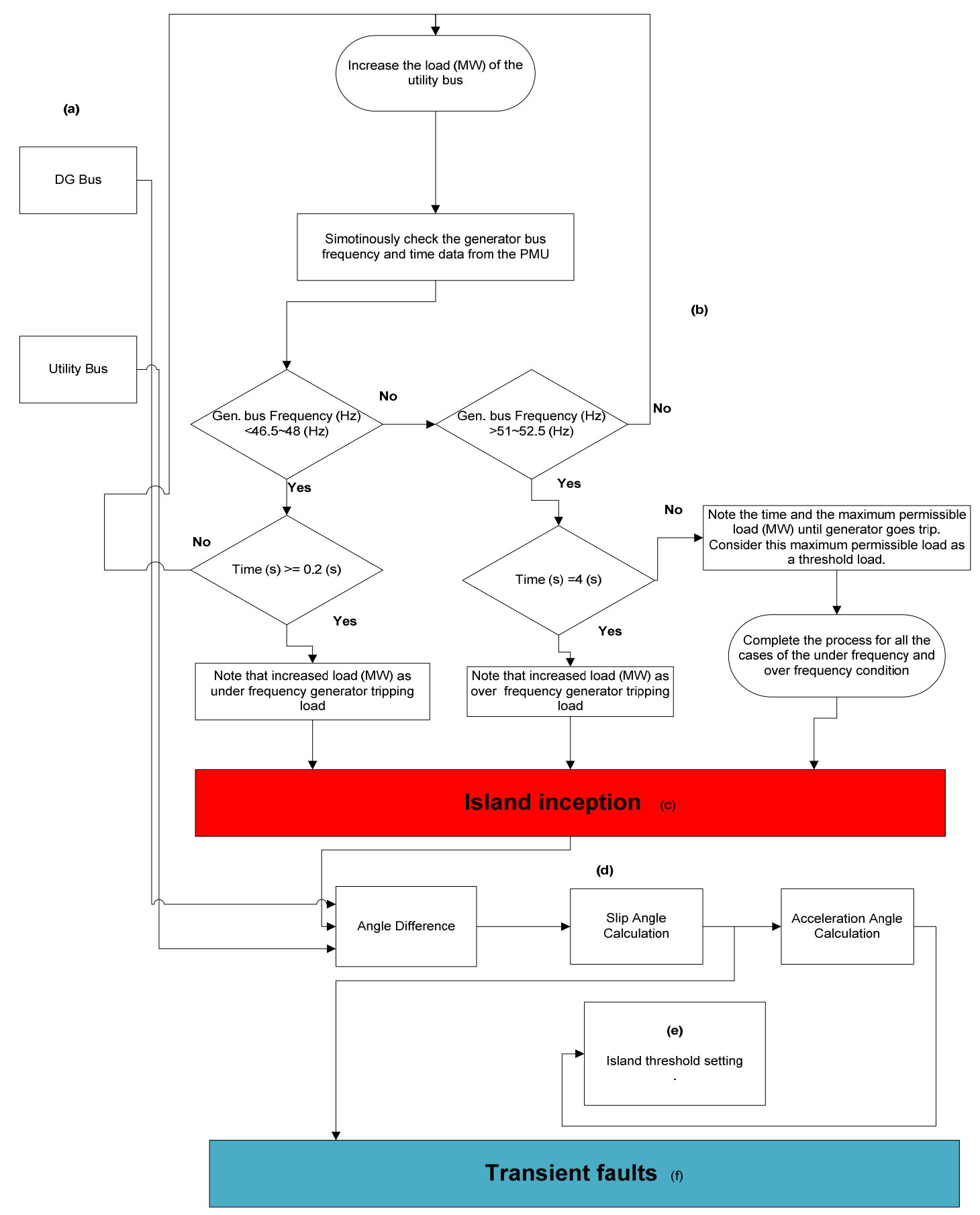

Figure 1. Proposed islanding threshold setting methodology.

Details of the proposed islanding detection threshold setting methodology are as follows: (a) Bus

It is critical to know which buses we can use for our calculation when determining the island threshold setting. Figure 1 depicts two buses, one of which is a DG bus and the other a utility bus. We used a modified IEEE 30 bus system in this research work, and there were two DG buses: Bus 11 (33 KV) and Bus 13 (33 KV). In this research work, we considered Bus 13 (33 KV), and for the utility buses, Bus $3(\mathrm{KV})$.

(b) Determining Load Threshold

Different load values result in different network conditions. From Figure 1, it is evident that the load could be increased until the generator loses its synchronism [43]. 
However, the under-frequency condition allows the generator to trip $0.2 \mathrm{~s}$ at a frequency less than $46.5 \sim 48 \mathrm{~Hz}$, and the over-frequency condition allows the generator to trip $4 \mathrm{~s}$ at a frequency greater than $51 \sim 52.5 \mathrm{~Hz}$ [42]. Only a permissible load can be determined for under-frequency and over-frequency conditions from there.

\section{(c) Island Inception}

Islanding occurs when generators and loads are disconnected from the main system but remain energized [4]. Voltage and frequency fluctuate, resulting in power quality degradation and synchronization issues on the utility grid.

\section{(d) Threshold Value Calculation}

This section consists of three important calculation segments: the angle difference, slip angle, and acceleration angle. From the PMU voltage angle data, the voltage angle difference between DG bus and utility bus is calculated, then using (1) and (2) the slip angle and acceleration angle value are calculated.

\section{(e) Island Threshold Setting}

Once all of the PMU slip angle and acceleration angle data from (d) have been calculated, a common threshold value can be created that will be applicable to all cases of under-frequency and over-frequency island conditions.

\section{(f) Transient Faults}

A substantial segment of this proposed methodology is to distinguish transient faults from the island. To figure out the transient faults threshold, the following steps are carried out:

Step 1. Perform fault current analysis at the utility buses.

Step 2. Find out the highest fault current bus.

Step 3. Create transient faults at the highest fault current bus by allowing $100 \mathrm{~ms}$ as fault clearing time according to [44].

Step 4. Get the voltage angle data of the transient faults.

Step 5. Calculate the slip angle from the voltage angle data using Equation (1).

Step 6. Take the maximum slip angle value from that $100 \mathrm{~ms}$ region as a transient fault threshold.

\section{Simulation}

This section discusses details of the test power system model. In Figure 2 there are three scenarios in this test system network. Details of the test system scenarios are as follows.

\section{Scenario 1}

The Bus 4 (132 KV) to Bus 12 (32 KV) interconnection point is connected, where Scenario 2 and Scenario 3 will both remain open. In this scenario Bus 4 (132 KV) imports power from Bus $12(33 \mathrm{KV})$ to feed the connected load.

\section{Scenario 2}

In this case Scenario 1 is opened and the DG side is connected with the Bus 6 (132 KV). Here the interconnection point between Bus $6(132 \mathrm{~V})$ and Bus $9(33 \mathrm{KV})$ is connected and Bus 9 (132 KV) exports power to Bus $6(132 \mathrm{KV})$ to feed the Bus $4(132 \mathrm{KV})$ connected load.

\section{Scenario 3}

In this scenario interconnections of Scenario 1 and Scenario 2 are both opened. Here the interconnection point between Bus $6(132 \mathrm{KV})$ and Bus $10(33 \mathrm{KV})$ is connected and Bus 10 $(132 \mathrm{KV})$ exports power to Bus $6(132 \mathrm{KV})$ to feed the Bus $4(132 \mathrm{KV})$ connected load. 


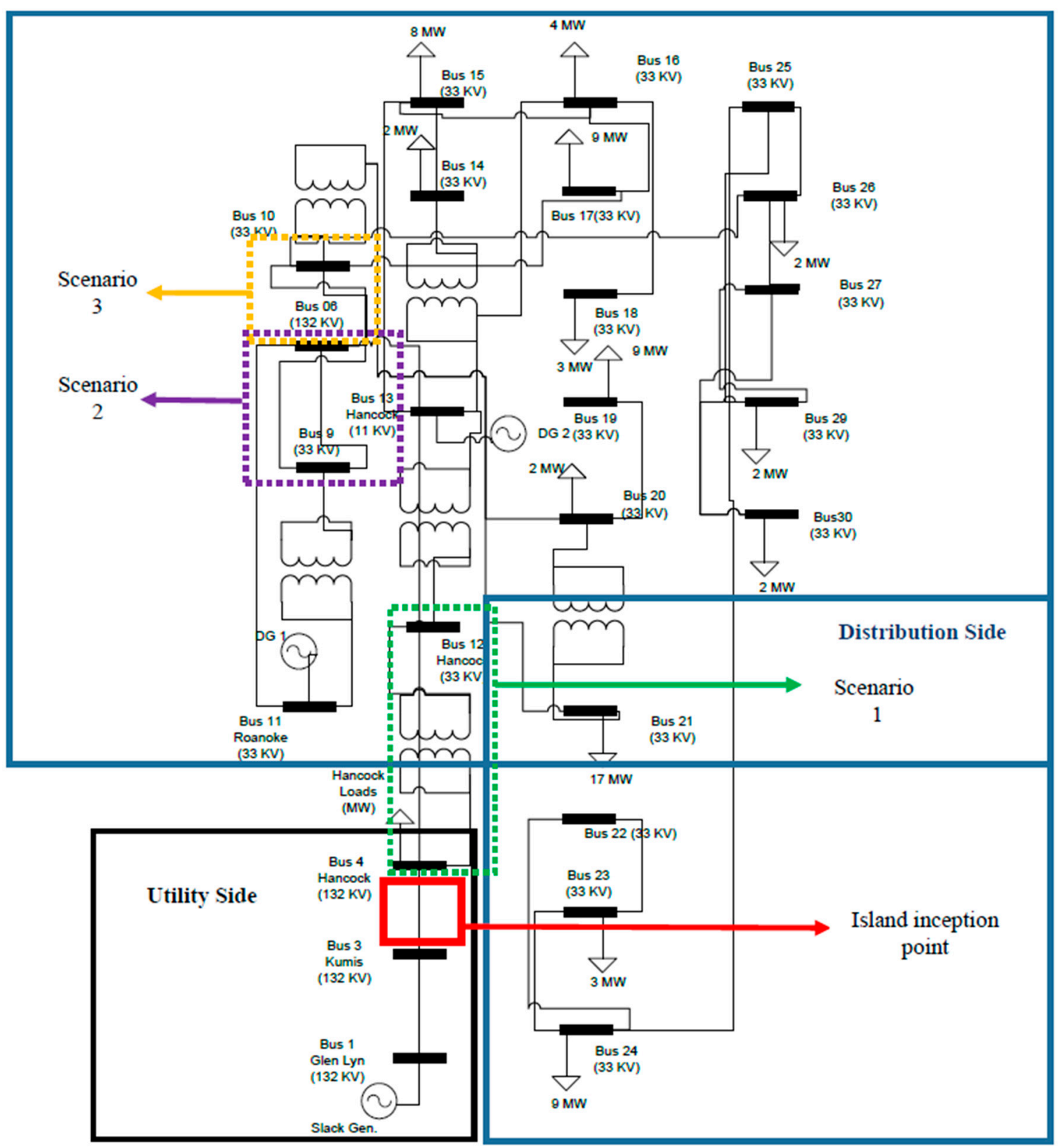

Figure 2. Single-line diagram of the modified IEEE 30 bus test system.

Tables 1 and 2 present the parameters of the simulated power system model and data preparation. PMU data was prepared using a PowerWorld simulator.

Table 1. Parameters of the test system.

\begin{tabular}{|c|c|c|c|c|c|c|c|c|c|}
\hline \multirow{2}{*}{ Cases } & \multicolumn{2}{|c|}{ Interconnection Points } & \multirow{2}{*}{ Scenarios } & \multirow{2}{*}{$\begin{array}{l}\text { Threshold Loads } \\
\text { of Bus } 4 \text { (132 KV) }\end{array}$} & \multirow{2}{*}{ Conditions } & \multicolumn{2}{|c|}{ DG1 } & \multicolumn{2}{|c|}{ DG2 } \\
\hline & To Bus & From Bus & & & & MW & MVAR & MW & MVAR \\
\hline A1 & 4 & 12 & 1 & $0.5 \mathrm{MW}$ & \multirow{3}{*}{ Over frequency } & \multirow{8}{*}{72} & 27 & \multirow{8}{*}{48} & 21 \\
\hline A2 & 6 & 9 & 2 & $0.80 \mathrm{MW}$ & & & 67 & & 29 \\
\hline $\mathrm{A} 3$ & 6 & 10 & 3 & $1.10 \mathrm{MW}$ & & & 38 & & 38 \\
\hline B1 & 4 & 12 & 1 & $18.600 \mathrm{MW}$ & \multirow{3}{*}{ Under frequency } & & 25 & & 22 \\
\hline B2 & 6 & 9 & 2 & $18.85 \mathrm{MW}$ & & & 67 & & 28 \\
\hline B3 & 6 & 10 & 3 & $18.150 \mathrm{MW}$ & & & 19 & & 37 \\
\hline $\mathrm{F} 1$ & 4 & 12 & 1 & $0.5 \mathrm{MW}$ & $\begin{array}{l}\text { Single line to ground } \\
\text { (SLG) fault }\end{array}$ & & 27 & & 21 \\
\hline F2 & 4 & 12 & 1 & $0.5 \mathrm{MW}$ & $\begin{array}{l}\text { Three-phase balance } \\
\text { (3PB) fault }\end{array}$ & & 27 & & 21 \\
\hline
\end{tabular}


Table 2. Data preoperational parameters of the test system.

\begin{tabular}{cc}
\hline Name of the Parameters & Settings \\
\hline System frequency & $50 \mathrm{~Hz}$ \\
\hline DG bus & Bus 13 (Hancock) \\
\hline Utility bus & Bus 3 (Kumis) \\
\hline Island event & Open the line between Bus 3 and 4 \\
\hline Island incepted & $0.02 \mathrm{~s}$ \\
\hline Time step &
\end{tabular}

\section{Results and Discussion}

This section discusses the results of the cases. The axes in Figures 3, 4 and 6-8 and ?? follow the Table 3 .

Table 3. Axis setting for the figures.

\begin{tabular}{ccc}
\hline \multirow{2}{*}{ Figures } & \multicolumn{3}{c}{ Legends } \\
\cline { 2 - 3 } & x-axis & y-axis \\
\hline 3,5 & Timestamp & Frequency \\
\hline $4,6,7,8$ & Timestamp & Voltage angle \\
\hline
\end{tabular}

\subsection{Case $A 1, A 2$, and $A 3$}

Cases A1, A2, and A3 represent the bus frequency of the islanding conditions when the interconnection points went from Bus 4 to Bus 12, from Bus 9 to Bus 10, and from Bus 6 to Bus 9, and the DG was greater than the connected feeder load or the overfrequency condition.

Figures 3 and 4 present the case A1 bus frequency and voltage angle of the DG and utility bus. Figure 3 is after incepting the island at a $2 \mathrm{~s}$ frequency, going up over the time and creating an over-frequency condition. The voltage angle profile of that condition at that moment is shown in Figure 4. The bus frequency and bus angle of cases A2 and A3 showed approximately similar behavior, according to Figures 3 and 4 .

Table 4 presents the thresholds results of cases A1, A2, and A3. The calculation was conducted using Equations (1) and (2) from the Figure 4 voltage angle data. From Table 4, the highest slip angle and acceleration was figured out for case A1, and the lowest one was seen in case $\mathrm{A} 2$ at a time of $20 \mathrm{~ms}$.

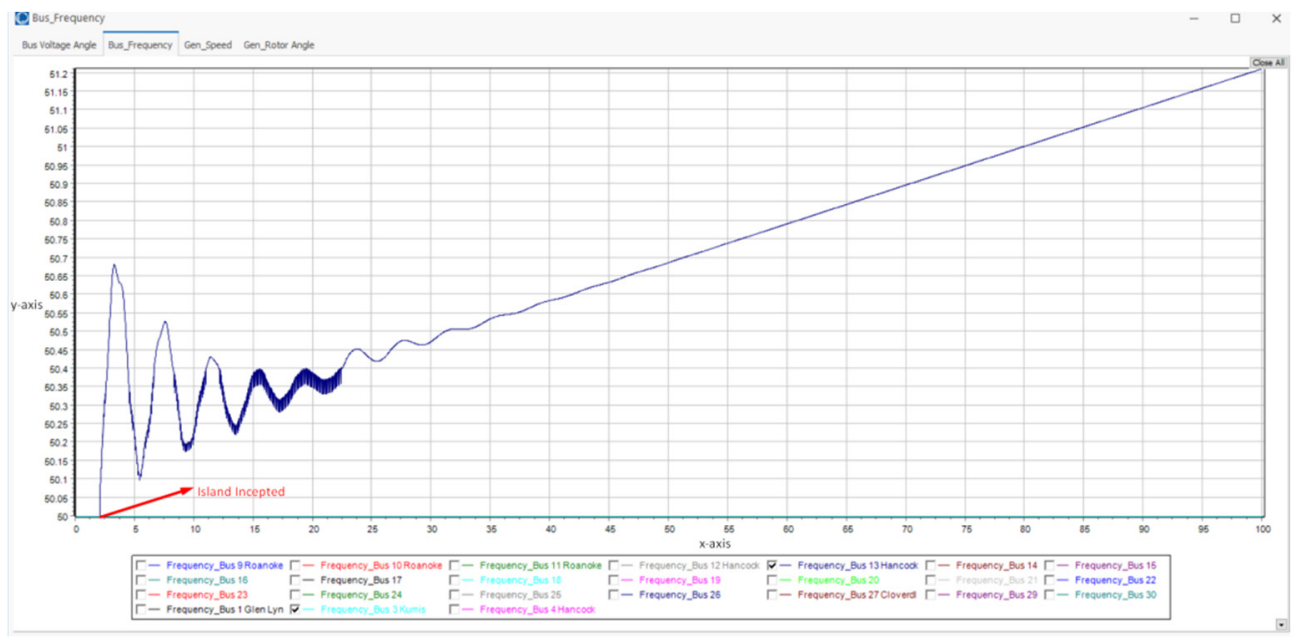

Figure 3. Case A1: DG and utility bus frequency. 


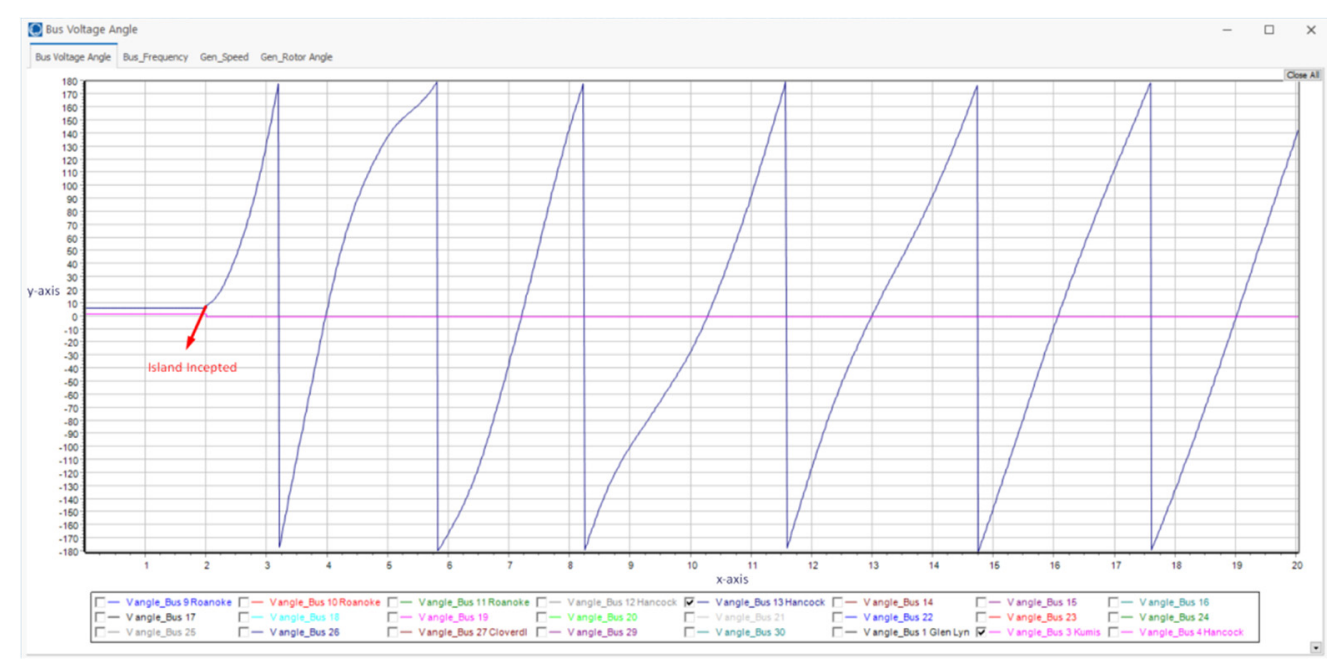

Figure 4. Case A1: DG and utility bus voltage angle.

Table 4. Threshold setting results of cases A1, A2, and A3.

\begin{tabular}{cccc}
\hline Cases & Slip Angle (Deg/s) & Acceleration Angle (Deg) & Time \\
\cline { 1 - 3 } A1 & 169.815 & 5490.75 & \\
\cline { 1 - 3 } A2 & 90.85 & 4542.5 & \\
\hline A3 & 91.81 & 4590.5 & \\
\hline
\end{tabular}

\subsection{Cases B1, B2, and B3}

Cases B1, B2, and B3 represented the bus frequency of the islanding conditions when the interconnection points went from Bus 4 to Bus 12, from Bus 9 to Bus 10, and from Bus 6 to Bus 9, and the DG was less than the connected feeder load or the under-frequency condition.

Figure 6 and ?? illustrate the bus frequency and voltage angle of the DG and utility bus for case B1. Figure 6 is after incepting the island at $2 \mathrm{~s}$ frequency, going downward over time and creating an under-frequency condition. The voltage angle profile of that condition at that moment is presented in Figure ?? The bus frequency and bus angle of cases B2 and B3 showed an approximately similar pattern, according to Figure 6 and ??.

For cases B1, B2, and B3 the values were comparatively smaller than cases A1, A2, and $\mathrm{A} 3$ due to the distance between the interconnection point and the placement of the PMU. The calculation in Table 5 for each case was conducted using Equations (1) and (2) from the Figure ?? voltage angle data. The maximum and minimum slip angle and acceleration angle in Table 4 are for case B3 and case B1, respectively.

Table 5. Threshold setting results of cases B1, B2, and B3.

\begin{tabular}{cccc}
\hline Cases & Slip Angle (Deg/s) & Acceleration Angle (Deg) & Time \\
\hline B1 & 0.525 & 26.25 & \\
B2 & 1.5 & 75 & $20 \mathrm{~ms}$ \\
\hline B3 & 2.54 & 127 & \\
\hline
\end{tabular}




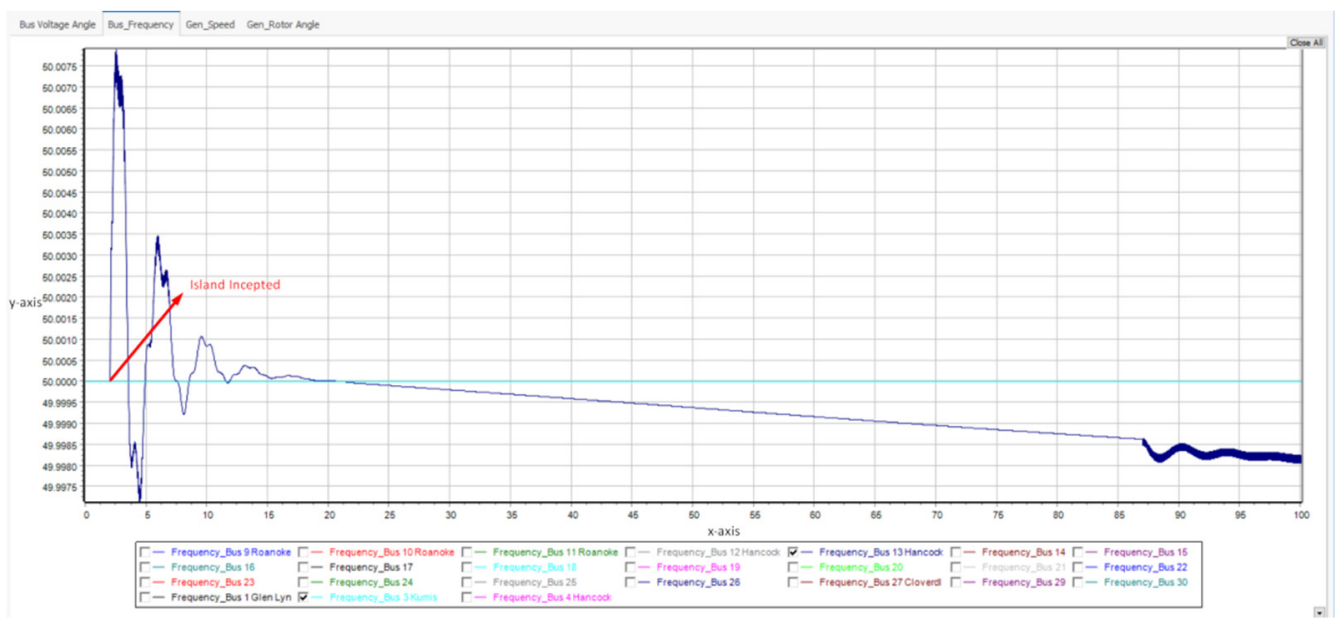

Figure 5. Case B1: DG and utility bus frequency.

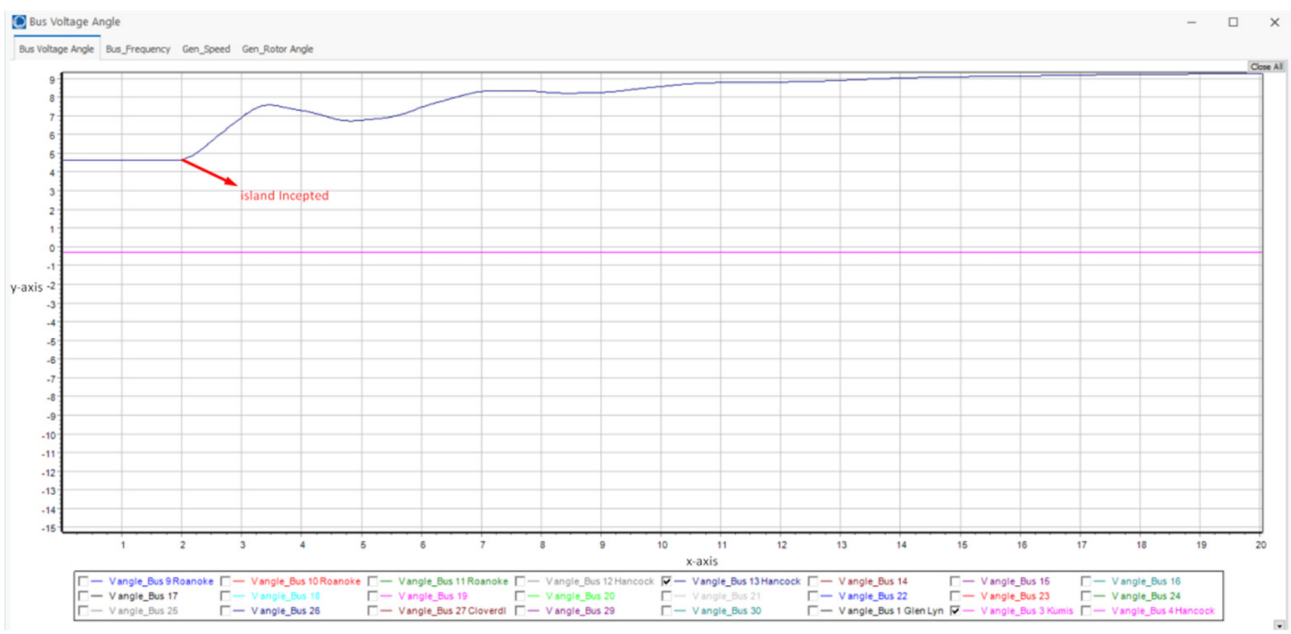

Figure 6. Case B1: DG and utility bus frequency.

\subsection{Case F1 and F2}

Cases F1 and F2 represent the single line to ground fault and three-phase balance fault event in the distribution network. The single line to ground fault was applied at the highest fault current (3.31900 P.U) bus, which was Bus 3, and the three-phase fault was applied at Bus 4 , where the fault current was 6.47348 P.U.

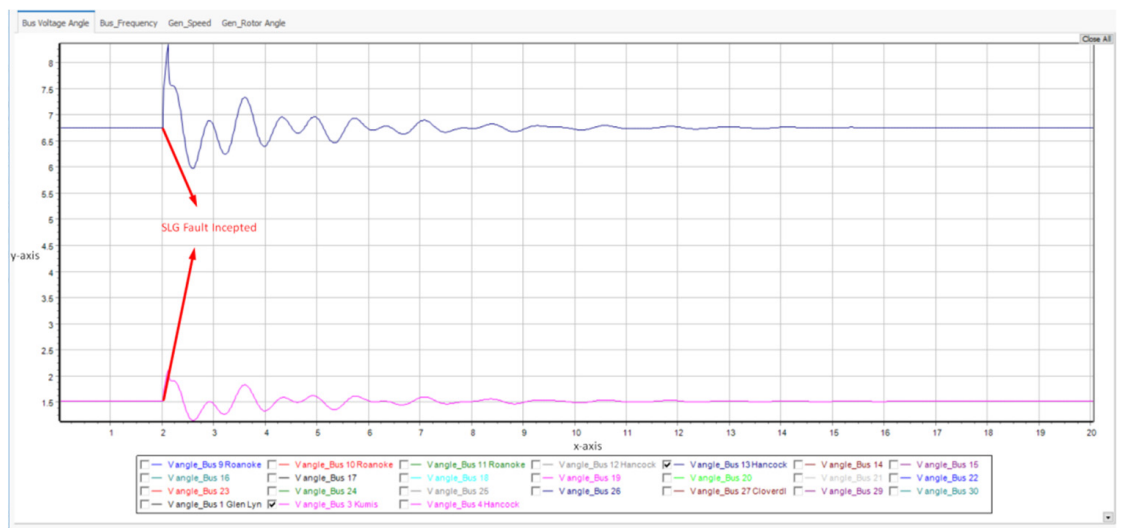

Figure 7. Case F1: DG and utility bus voltage angle. 


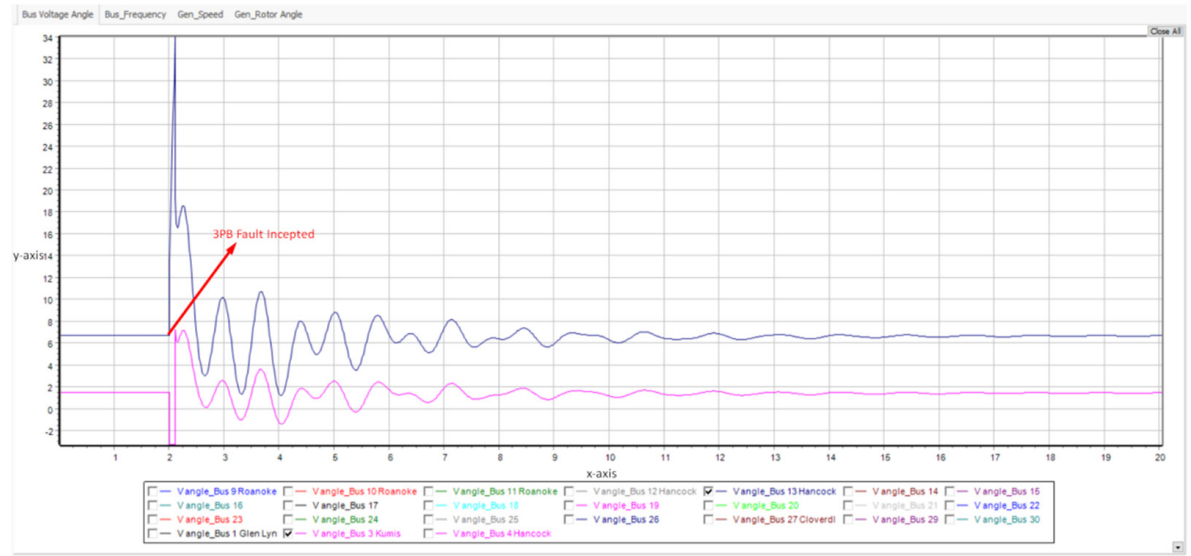

Figure 8. Case F2: DG and utility bus voltage angle.

Figures 7 and 8 show the transient fault incepting point and the DG and utility bus voltage angle behaviors of cases F1 and F2. Table 6 presents the transient fault thresholds of case F1 and case F2, where the slip angle was calculated using Equation (1) from the voltage angle data in Figures 7 and 8.

Table 6. Threshold results of case F1 and case F2.

\begin{tabular}{ccc}
\hline Cases & Slip Angle (Deg/s) & Time \\
\cline { 1 - 2 } F1 & 14.57 & $20 \mathrm{~ms}$ \\
\cline { 1 - 2 } F2 & 503.945 & \\
\hline
\end{tabular}

\subsection{Threshold Setting}

Considering islanding cases A1 to B3, we came out with a common threshold that will be applicable for all cases to differentiate between islanding events and transient fault events. Table 7 shows the islanding threshold and the transient fault threshold for the islanding detection algorithm.

Table 7. Threshold settings for the islanding detection algorithm.

\begin{tabular}{ccl}
\hline $\begin{array}{c}\text { Slip Angle } \\
\text { (Deg/s) }\end{array}$ & $\begin{array}{c}\text { Acceleration Angle } \\
\text { (Deg) }\end{array}$ & Thresholds \\
\hline 0.525 & 26.25 & Islanding threshold \\
\hline 14.57 & NA & SLG fault threshold \\
\hline 503.945 & NA & 3PB fault threshold \\
\hline
\end{tabular}

\subsection{Results Comparison}

Table 8 shows the results of a comparative analysis of the proposed algorithm with other recent methods. It shows that in [45-49], the transient fault events that are crucial in islanding detection were not analyzed, whereas [41,50-52] showed a higher detection time and [53-55] was unable to figure out the islanding detection time. However, [56] shows less detection time by considering transient faults but compare to the proposed algorithm that detection time [56] is bit higher. 
Table 8. Comparison of results with other islanding detection methods.

\begin{tabular}{cccc}
\hline Ref. & Methods & Transient Faults & Detection Time \\
\hline$[45]$ & WSE & Not considered & $<10 \mathrm{~ms}$ \\
\hline$[46]$ & ST & Not considered & $26 \mathrm{~ms}$ \\
\hline$[47]$ & EMD & Not considered & $<35 \mathrm{~ms}$ \\
\hline$[48]$ & TMF & Not considered & $55 \mathrm{~ms}$ \\
\hline$[49]$ & VMD & Not considered & $10 \mathrm{~ms}$ \\
\hline$[50]$ & ANN & Considered & $0.5 \mathrm{~s}$ \\
\hline$[51]$ & SVM & Considered & $50 \mathrm{~ms}$ \\
\hline$[52]$ & HoGF+ SVMs & Considered & $218 \mathrm{~ms}$ \\
\hline$[53]$ & ELM & Considered & $\mathrm{NA}$ \\
\hline$[54]$ & Ensemble tree & Considered & $\mathrm{NA}$ \\
\hline$[55]$ & RF & Considered & $\mathrm{NA}$ \\
\hline$[56]$ & MIMF & Considered & $<70 \mathrm{~ms}$ \\
\hline$[41]$ & Slip frequency and acceleration & Considered & $500 \mathrm{~ms}$ \\
\hline & Proposed method & Considered & $20 \mathrm{~ms}$ \\
\hline
\end{tabular}

As shown in Table 8, [50-56] considered transient faults outside the utility grid, where the proposed method focused on the inside of the utility grid. As island occurs when the utility side opens from the distribution side, so it is important to scrutinize the transient fault inside the utility grid. However, [41] considered transient faults inside the utility grid but managed a higher island detection time of 500 mile seconds. On the other hand, the proposed method showed a better island detection time of 20 mile seconds compared to the other methods. In addition, like other methods, the proposed method follows IEEE standard 1547, which is $2 \mathrm{~s}$, so it can be used in a real power system to detect islands.

\section{Conclusions}

The motivation of this research work was to detect islanding events for underfrequency and over-frequency systems. To detect islanding events, it is very important to set a proper threshold, because an inappropriate threshold can increase the islanding detection time. The following are the important discussion points:

- This research work proposed a novel islanding threshold setting method using the slip angle and acceleration angle.

- The proposed research work overcame the limitation of the local area-based islanding detection threshold setting.

- The proposed research method can distinguish the actual islanding event and the transient fault event.

Future work will develop an islanding detection algorithm to detect the "big island" in the Utility Kerteh, Malaysia system using this proposed threshold setting methodology. 
Author Contributions: A.A.A. developed the methodology, performed the literature review, prepared the data, and wrote, reviewed, and edited the entire manuscript. M.F.R. as a supervisor followed up on all steps, gave helpful advice to write the manuscript, and reviewed and edited the manuscript. N.S. as a co-supervisor reviewed and edited the manuscript. M.F.A. as a field supervisor followed up on all steps and gave helpful advice to prepare the data and assisted to write the manuscript. K.N.B.M.H. and N.B.M.N. reviewed the manuscript. M.L.O. reviewed and edited the manuscript. All authors have read and agreed to the published version of the manuscript.

Funding: This research was funded by Yayasan Universiti Teknologi PETRONAS (YUTP) grant No. YUTP-015LC0-167 and this APC was funded collaboratively by Universiti Teknologi PETRONAS and Universiti Putra Malaysia.

Acknowledgments: The authors are thankful to the Yayasan Universiti Teknologi PETRONAS (YUTP) grant No. YUTP-015LC0-167 and Universiti Putra Malaysia named Geran Putra Berimpak, with ref. UPM/800-3/3/1/GPB/2019/9671700.

Conflicts of Interest: The authors declare no conflict of interest.

\section{References}

1. Khamis, A.; Shareef, H.; Bizkevelci, E.; Khatib, T. A review of islanding detection techniques for renewable distributed generation systems. Renew. Sustain. Energy Rev. 2013, 28, 483-493. [CrossRef]

2. Kumar, P.; Kumar, V.; Tyagi, B. Islanding detection for reconfigurable microgrid with RES. IET Transm. Distrib. 2021, 15, 1187-1202. [CrossRef]

3. Seong-Cheol, K.; Ray, P.; Salkuti, S.R. Islanding detection in a distribution network with distributed generators using signal processing techniques. Int. J. Power Electron. Drive Syst. 2020, 11, 2099-2106.

4. Motter, D.; Vieira, J.C. Improving the islanding detection performance of passive protection by using the undervoltage block function. Electr. Power Syst. Res. 2020, 184, 106293. [CrossRef]

5. Abdelsalam, A.A.; Salem, A.A.; Oda, E.S.; Eldesouky, A.A. Islanding detection of microgrid incorporating inverter based DGs using long short-term memory network. IEEE Access 2020, 8, 106471-106486. [CrossRef]

6. Khichar, S.; Lalwani, M. An analytical survey of the islanding detection techniques of distributed generation systems. Technol. Econ. Smart Grids Sustain. Energy 2018, 3, 1-10. [CrossRef]

7. Azim, R.; Li, F.; Xue, Y.; Starke, M.; Wang, H. An islanding detection methodology combining decision trees and Sandia frequency shift for inverter-based distributed generations. IET Gener. Transm. Distrib. 2017, 11, 4104-4113. [CrossRef]

8. Zamani, R.; Golshan, M.E.H.; Alhelou, H.H.; Hatziargyriou, N. A novel hybrid islanding detection method using dynamic characteristics of synchronous generator and signal processing technique. Electr. Power Syst. Res. 2019, 175, 10591. [CrossRef]

9. Babakmehr, M.; Dehghanian, F.H.P.; Enslin, J. Artificial intelligence-based cyber-physical events classification for islanding detection in power inverters. IEEE J. Emerg. Sel. Top. Power Electron. 2020. [CrossRef]

10. Reddy, C.R.; Goud, B.S.; Reddy, B.N.; Pratyusha, M.; Kumar, C.V.; Rekha, R. Review of islanding detection parameters in smart grids. In Proceedings of the 2020 8th IEEE International Conference on Smart Grid (icSmartGrid), Paris, France, 17 June 2020; pp. 78-89.

11. Wang, X.; Freitas, W.; Dinavahi, V.; Xu, W. Investigation of positive feedback anti-islanding control for multiple inverter-based distributed generators. IEEE Trans. Power Syst. 2009, 24, 785-795. [CrossRef]

12. Lopes, L.A.; Zhang, Y. Islanding detection assessment of multi-inverter systems with active frequency drifting methods. IEEE Trans. Power Deliv. 2007, 23, 480-486. [CrossRef]

13. Zhou, B.; Cao, C.; Li, C.; Cao, Y.; Chen, C.; Li, Y.; Zeng, L. Hybrid islanding detection method based on decision tree and positive feedback for distributed generations. IET Gener. Transm. Distrib. 2018, 9, 1819-1825. [CrossRef]

14. Khodaparastan, M.; Vahedi, H.; Khazaeli, F.; Oraee, H. A novel hybrid islanding detection method for inverter-based DGs using SFS and ROCOF. IEEE Trans. Power Deliv. 2015, 32, 2162-2170. [CrossRef]

15. Chandak, S.; Mishra, M.; Rout, P.K. Hybrid islanding detection with optimum feature selection and minimum NDZ. Int. Trans. Electr. Energy Syst. 2018, 28, e2602. [CrossRef]

16. Faqhruldin, O.N.; El-Saadany, E.F.; Zeineldin, H.H. A universal islanding detection technique for distributed generation using pattern recognition. IEEE Trans. Smart Grid 2014, 5, 1985-1992. [CrossRef]

17. Mishra, M.; Chandak, S.; Rout, P.K. Taxonomy of islanding detection techniques for distributed generation in microgrid. Renew. Energy Focus 2018, 31, 9-30. [CrossRef]

18. Buduma, P.; Pinto, S.J.; Panda, G. Loss of utility detection and seamless operation of distributed generation system. IEEE Trans. Ind. Appl. 2020, 56, 3149-3158. [CrossRef]

19. Xu, W.; Mauch, K.; Martel, S. An assessment of dg islanding detection methods and issues for canada, report\# cetc-varennes 2004-074 (tr), canmet energy technology centre-varennes. Nat. Resour. Can. July 2004, 53. 
20. Micky, R.; Sunitha, R.; Ashok, S. Techno-Economic analysis of wams based islanding detection algorithm for microgrids with minimal pmu in smart grid environment. In Wide Area Power Systems Stability, Protection, and Security; Springer: Berlin/Heidelberg, Germany, 2020; pp. 499-522.

21. Guo, Y.; Li, K.; Laverty, D.M.; Xue, Y. Synchrophasor-based islanding detectin for distributed generation systems using systematic principal component analysis approaches. IEEE Trans. Power Deliv. 2015, 30, 2544-2552. [CrossRef]

22. Najda, V.M.; Gopakumar, P.; Sunitha, R. PMU based voltage angular dynamic monitoring and supervision system for emerging deregulated power grids. In Proceedings of the International Conference on Computer Communication and Informatics (ICCCI), Coimbatore, India, 23-25 January 2019; pp. 1-4.

23. Lidula, N.W.A.; Rajapakse, A.D. A pattern-recognition approach for detecting power islands using transient signals-Part II: Performance evaluation. IEEE Trans. Power Deliv. 2012, 27, 1071-1080. [CrossRef]

24. Galvan, F.; Wells, C.H. Detecting and managing the electrical island created in the aftermath of Hurricane Gustav using Phasor Measurement Unit (PMUs). In Proceedings of the IEEE PES T\&D, New Orleans, LA, USA, 19-22 April 2010; pp. 1-5.

25. Lin, Z.; Xia, T.; Ye, Y.; Zhang, Y.; Chen, L.; Liu, Y.; Tomsovic, K.; Bilke, T.; Wen, F. Application of wide area measurement systems to islanding detection of bulk power systems. IEEE Trans. Power Syst. 2013, 28, 2006-2015. [CrossRef]

26. Liu, X.; Laverty, D.M.; Best, R.J.; Li, K.; Morrow, D.J.; McLoone, S.S. Principal component analysis of wide-area phasor measurements for islanding detection-a geometric view. IEEE Trans. Power Del. 2015, 30, 976-985. [CrossRef]

27. Azim, R.; Sun, K.; Li, F.; Zhu, Y.; Saleem, H.A.; Shi, D.; Sharma, R. A comparative analysis of intelligent classifiers for passive island detection in micro-grids. In Proceedings of the IEEE Eindhoven PowerTech, Eindhoven, The Netherlands, 29 June 2015; pp. $1-6$.

28. Azim, R.; Zhu, Y.; Saleem, H.A.; Sun, K.; Li, F.; Shi, D.; Sharma, R. A decision tree-based approach for microgrid island detection. In Proceedings of the IEEE Power \& Energy Society Innovative Smart Grid Technologies Conference (ISGT), Washington, WA, USA, 18-20 February 2015; pp. 1-5.

29. Sun, R.; Centeno, V.A. Wide area system islanding contingency detecting and warning scheme. IEEE Trans. Power Syst. 2014, 29, 2581-2589. [CrossRef]

30. Alam, M.R.; Muttaqi, K.M.; Bouzerdoum, A. A multifeature-based approach for islanding detection of DG in the subcritical region of vector surge relays. IEEE Trans. Power Del. 2014, 29, 2349-2358. [CrossRef]

31. Hashiesh, F.; Mostafa, H.E.; Mansour, M.M.; Khatib, A.R.; Helal, I. Wide area transient stability prediction using on-line Artificial Neural Networks. In Proceedings of the Electric Power Conference, Vancouver, BC, Canada, 6-7 October 2008; pp. 1-7.

32. Arefin, A.A.; Hasan, K.N.M.; Romlie, M.F.; Abdullah, M.F.; Ali, M.L.; Othman, M.L. Determining islanding operation using micro grid phasor measurement unit parameters. Int. J. Emerg. Trends Eng. Res. 2020, 8, 97-101. [CrossRef]

33. Liu, X.A.; Laverty, D.; Best, R. Islanding detection based on probabilistic PCA with missing values in PMU data. In Proceedings of the IEEE PES General Meeting Conference \& Exposition, Washington, WA, USA, 27-31 July 2014; pp. 1-6.

34. Liu, X.; Kennedy, J.M.; Laverty, D.M.; Morrow, D.J.; McLoone, S. Wide-area phase-angle measurements for islanding detection-An adaptive nonlinear approach. IEEE Trans. Power 2017, 31, 1901-1911. [CrossRef]

35. Ohno, T.; Yasuda, T.; Takahashi, O.; Kaminaga, M.; Imai, S. Islanding protection system based on synchronized phasor measurements and its operational experiences. In Proceedings of the IEEE Power and Energy Society General Meeting-Conversion and Delivery of Electrical Energy in the 21st Century, Pittsburgh, PA, USA, 20-24 July 2008; pp. 1-5.

36. Kumar, D.; Bhowmik, P.S. Wide area islanding detection using phasor measurement unit. In Proceedings of the IEEE 11th International Conference on Intelligent Systems and Control (ISCO), Coimbatore, India, 5-6 January 2017; pp. 49-54.

37. Chen, H.; Martin, K.; Bhargava, B.; Budhraja, V.; Balance, J. On-Line Islanding Detection Application in the RealTime Dynamics Monitoring System. In Proceedings of the IEEE PES T\&D Conference and Exposition, Chicago, IL, USA, 24 July 2014.

38. Ebrahim, M.A.; Wadie, F.; Abd-Allah, M.A. An algorithm for detection of fault, islanding, and power swings in dg-equipped radial distribution networks. IEEE Syst. J. 2019, 14, 3893-3903. [CrossRef]

39. Vatani, M.; Sanjari, M.J.; Gharehpetian, G.B. Islanding detection in multiple-DG microgrid by utility side current measurement. Int. Trans. Electr. Energy Syst. 2015, 25, 1905-1922. [CrossRef]

40. Ahmadipour, M.; Hizam, H.; Othman, M.L.; Radzi, M.A. Islanding detection method using ridgelet probabilistic neural network in distributed generation. Neurocomputing 2019, 329, 188-209. [CrossRef]

41. Mulhausen, J.; Schaefer, J.; Mynam, M.; Guzmán, A.; Donolo, M. Anti-islanding today, successful islanding in the future. In Proceedings of the 2010 IEEE 63rd Annual Conference for Protective Relay Engineers, College Station, TX, USA, 29 March-1 April 2010; pp. 1-8.

42. Ravikumar, K.G.; Upreti, A.; Nagarajan, A. State-of-the-Art islanding detection and decoupling systems for utility and industrial power systems. In Proceedings of the 69th Annual Georgia Tech Protective Relaying Conference, Atlanta, GA, USA, 29 April 2015.

43. Schwartfeger, L.; Santos-Martin, D.; Wood, A.; Watson, N.; Miller, A. Review of Distributed Generation Interconnection Standards, EEA Conference \& Exhibition: Auckland, The Newzealand, 2014.

44. Ahmad, I. A Lyapunov-based direct adaptive controller for the suppression and synchronization of a perturbed nuclear spin generator chaotic system. Appl. Math. Comput. 2021, 395, 125858.

45. Samui, A.; Samantaray, S.R. Wavelet singular entropy-based islanding detection in distributed generation. IEEE Trans. Power Del. 2013, 28, 411-418. [CrossRef] 
46. Ray, P.K.; Mohanty, S.R.; Kishor, N. Disturbance detection in grid connected distributed generation system using wavelet and S-transform. Elect. Power Syst. Res. 2011, 81, 805-819. [CrossRef]

47. Niaki, A.H.M.; Afsharnia, S. A new passive islanding detection method and its performance evaluation for multi-DG systems. Elect. Power Syst. Res. 2014, 110, 180-187. [CrossRef]

48. Dubey, R.; Popov, M.; Samantaray, S.R. Transient monitoring function-based islanding detection in power distribution network. IET Gener. Transm. Distrib. 2019, 13, 805-813. [CrossRef]

49. Admasie, S.; Bukhari, S.B.A.; Haider, R.; Gush, T.; Kim, C.-H. A passive islanding detection scheme using variational mode decomposition basedmode singular entropy for integrated microgrids. Elect. Power Syst. Res. 2019, 177, 105983. [CrossRef]

50. Kumar, D.; Bhowmik, P.S. Artificial neural network and phasor data-based islanding detection in smart grid. IET Gener. Transm. Distrib. 2018, 12, 5843-5850. [CrossRef]

51. Matik-Cuka, B.; Kezunovic, M. Islanding detection for inverter based distributed generation using support vector machine method. IEEE Trans. Smart Grid 2014, 5, 2676-2686. [CrossRef]

52. Manikonda, S.K.G.; Gaonkar, D.N. Islanding detection method based on image classification technique using histogram of oriented gradient features. IET Gener. Transm. Distrib. 2020, 14, 2790-2799. [CrossRef]

53. Mishra, M.; Sahani, M.; Rout, P.K. An islanding detection algorithm for distributed generation based on hilbert-huang transform and extreme learning machine. Sustain. Energy Grids Netw. 2017, 9, 13-26. [CrossRef]

54. Alshareef, S.; Talwar, S.; Morsi, W.G. A new approach based on wavelet design and machine learning for islanding detection of distributed generation. IEEE Trans. Smart Grid 2014, 5, 1575-1583. [CrossRef]

55. Adari, B.; Bhalja, B.B. Islanding detection of distributed generation using random forest technique. In Proceedings of the IEEE 6th International Conference on Power Systems, New Delhi, India, 4-6 March 2016; pp. 1-6.

56. Chaitanya, B.K.; Yadav, A.; Pazoki, M. Reliable islanding detection scheme for distributed generation based on pattern-recognition. IEEE Trans. Ind. Inform. 2020, 17, 5230-5238. [CrossRef] 